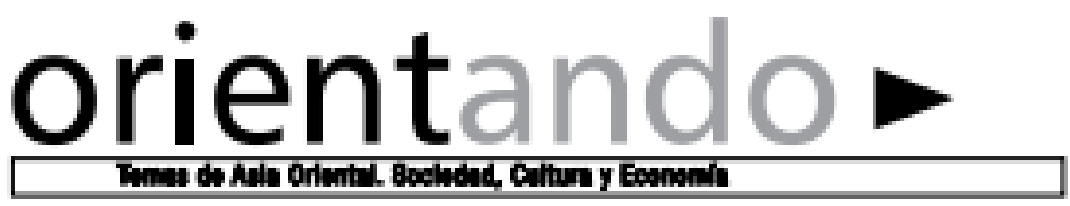

Año 10. Número 21. Octubre 2020-Marzo 2021

ISSN 2007-5723

Centro de Estudios China-Veracruz/Universidad Veracruzana

\title{
Reflexiones acerca del impacto de la crisis del coronavirus sobre las Mipymes mexicanas*
}

Li Yan

\section{Resumen:}

Desde el inicio del presente año, se ha producido el brote epidémico del coronavirus y la pandemia infecciosa se está propagando por todo el mundo. América Latina recientemente se ha convertido en el nuevo epicentro del Covid-19 tras los países asiáticos y europeos, siendo México uno de los países con mayor número de casos confirmados a nivel regional y la economía mexicana es fuertemente afectada por el rápido avance de la pandemia.

Este trabajo tiene como objetivo realizar un análisis de los efectos de la pandemia del coronavirus en las Mipymes en México. A pesar de ser los “motores económicos” del país, han sufrido consecuencias más graves de la pandemia, ya que la crisis sanitaria afectó gravemente su funcionamiento, dificultando su participación en el financiamiento del mercado, obstaculizando su producción e intercambio normal con el exterior, todo lo cual se complementa con el consecuente aumento del desempleo, la reducción de los ingresos fiscales y la disminución en el volumen comercial. Para ayudarles a resolver los problemas relevantes y paliar las enormes dificultades que enfrentan, el Gobierno mexicano ha tomado una serie de medidas emergentes como la emisión de préstamos preferenciales, las entidades financieras internacionales han prestado apoyos crediticios a pequeñas entidades. Al darse cuenta de la importancia de que goza la digitalización en los momentos

\footnotetext{
* This paper is supported by the Fundamental Research Funds for the Central Universities, and the Research Funds of Renmin University of China ( 16XNF028 ) .
} 
más delicados, una gran mayoría de las Pymes mexicanas han llevado a cabo una "transformación digital" para adaptarse mejor a la coyuntura desfavorable.

Al final del trabajo, se comenta que si bien las políticas pertinentes pueden ayudar a aliviar en cierta medida los impactos, en la era posterior a la crisis de la "nueva normalidad", las Mipymes mexicanas deberían elaborar sus propios planes de desarrollo, fomentando continuamente las relaciones con grandes empresas, y promoviendo sólidamente la modernización de las mismas, al tener el respaldo de unas políticas públicas más inclusivas por parte del Gobierno en el futuro.

Palabras clave: coronavirus, Mipymes, impacto de crisis, estrategias de respuesta.

\section{Abstract:}

Since the beginning of this year, the epidemic outbreak of the coronavirus has occurred and the infectious pandemic is spreading throughout the world. Latin America has recently become the new epicenter of Covid-19 after Asian and European countries, with Mexico being one of the countries with the highest number of confirmed cases at the regional level and the Mexican economy strongly affected by the speedy advance of the pandemic.

This research work aims to carry out an analysis of the effects of the coronavirus pandemic on MSMEs in Mexico. Despite being the "economic engines" of the country, MSMEs have experienced more serious consequences from the pandemic, since the health crisis seriously affected their operation, hindering their participation in the financing of the market, hampering their production and normal exchange with the abroad, all of which is complemented by the consequent increase in unemployment, the reduction in tax revenues and the decrease in commercial volume. In order to help them solve the relevant problems and alleviate the enormous difficulties they face, the Mexican Government has taken a series of emerging measures such as the issuance of preferential loans, international financial entities have provided credit support to small ones. A great majority of Mexican SMEs have carried out a "digital transformation" to better adapt to the unfavorable situation when they realize of the importance of digitization in the most delicate moments.

At the end of this research, it is commented that although the pertinent policies can help to alleviate the impacts to some extent, in the post-crisis era of the "new normal", Mexican MSMEs should elaborate their own development plans, continuously promoting relations with large

Orientando. Temas de Asia Oriental. Sociedad, Cultura y Economía. Revista editada por el Centro de Estudios China-Veracruz de la Universidad Veracruzana, México (Centro de Estudios APEC) / año 10 / número 21/ 
companies, and solidly promoting their modernization, having the support of more inclusive public policies by the Government in the future.

Keywords: Coronavirus, MSMEs, Impact of crisis, response strategies.

\section{Introducción}

Desde el principio del presente año hasta el 8 de agosto de 2020, con un alto índice de propagación del coronavirus, América Latina ha "superado" otras regiones con casos confirmados superiores a 5.3 millones y casos muertes superiores a 210, 000, convirtiéndose en el nuevo epicentro epidémico al nivel mundial. Brasil, México, Perú, Chile, Colombia y Argentina han llegado a ser los países con mayor número de casos confirmados del contagio en la región. La pandemia ha causado graves daños a las economías de América Latina, que ya habían mantenido un ritmo desacelerado de crecimiento durante los siete años consecutivos anteriores a la crisis sanitaria. De 2014 a 2019, la tasa promedio de crecimiento anual de la economía regional fue de solo 0.4\%; la Comisión Económica de las Naciones Unidas para América Latina y el Caribe (CEPAL) disminuyó la expectativa del crecimiento del país hasta $-5.3 \%$, número récord a lo largo de la historia, e incluso más bajo que la de las dos Grandes Depresiones en 1930 y 1914, que fueron - 5\% y -4.9\%, respectivamente.

Antes del estallido de la pandemia, México ya había entrado a una recesión económica en 2019 (-0.1\% del PIB), ya que la situación macroeconómica y las finanzas públicas del país llegaron a un nivel muy preocupante con el débil crecimiento económico interno, el deterioro de las finanzas públicas, así como el estancamiento y la contracción de los sectores de servicios y las actividades industriales desde el mismo año. Según los datos de la Organización para el Desarrollo Económico y Cooperativo (OCDE), en los años 2017 y 2018, los ingresos fiscales públicos de México ocuparon el último lugar entre los países miembros de la OCDE. En 2019, los ingresos públicos de los demás miembros representaron el 34.3\% del PIB, mientras que el porcentaje en México fue el 16.1\%. Dado que los ingresos petroleros son una fuente importante de los ingresos fiscales de México, la fuerte caída de la

Orientando. Temas de Asia Oriental. Sociedad, Cultura y Economía. Revista editada por el Centro de Estudios 
producción petrolera en 2019 provocó una fuerte caída de los ingresos al respecto, de manera que el Gobierno tuvo que acudir al fondo de estabilización presupuestaria para mantener el funcionamiento normal de la industria petrolera. Además, la deuda pública continuó deteriorándose y la deuda pública acumulada como proporción del PIB para el periodo 20142019, aumentó de 37\% a 45\%, lo que fue calificado como perspectiva negativa por Moody's y Standard \& Poor's. ${ }^{1}$

Con la llegada del coronavirus, las industrias de turismo, energía y manufactura de México han sido los primeros sectores en sufrir, lo que provocó una desaceleración del crecimiento económico, la agitación del mercado financiero, el cierre de gran número de

empresas y el aumento de población desocupada. El impacto provocado por el coronavirus es mayor que el de la "Gripe porcina" de 2009. De acuerdo con las previsiones del Banco Central de México, la tasa de crecimiento económico interno se reduciría en $3.5 \%$ en 2020, y el Fondo Monetario Internacional estimó que la economía mexicana disminuyó en 6.6\%. Instituciones más pesimistas previeron que la contracción del crecimiento económico de México sería de $8.5 \%$ a $10.5 \%$.

\section{Situación básica de las Mipymes mexicanas}

Las Mipymes mexicanas se remontan al período de industrialización de la década de 1930 y han experimentado un rápido desarrollo desde 1950 hasta mediados de 1960, cuando la Secretaría de Industria y Comercio (SIC) anunció de manera oficial el establecimiento del Programa de Industrialización Fronteriza (PIF). Un mes más tarde emitió las reglas y los lineamientos correspondientes en donde se estipula que, en la franja de 20 kilómetros a lo largo de la frontera norte con EE.UU., la materia prima y los componentes orginales podrían importarse a México exentos de impuestos para emsamblarse y luego reexportarse en zonas

1新华网. 拉美各国新冠死亡数据为何出现两极分化. 2020 年 8 月 8 日 http://www.xinhuanet.com/2020-08/08/c_1126343352.htm

Orientando. Temas de Asia Oriental. Sociedad, Cultura y Economía. Revista editada por el Centro de Estudios China-Veracruz de la Universidad Veracruzana, México (Centro de Estudios APEC) / año 10 / número 21/ 
francas $^{2}$, lo que fomentó enormemente el desarrollo y la prosperidad de la exportación de la región y al mismo tiempo estimuló el rápido desarrollo de las Mipymes locales. Con la firma del Tratado de Libre Comercio de América del Norte (TLCAN) en 1994, el centro industrial de México se iba trasladando al norte del país y las Pymes se hicieron cada vez más importantes en las regiones central y norte. El "Acuerdo Estados Unidos-México-Canadá” (T-MEC) que entró en vigencia el 1 de julio de 2020 reafirmó el papel de las mismas, señalando que éstas sirven de motores para el desarrollo económico de todo el país mexicano e incluso de toda la región de América del Norte.

Hoy en día, aún no existe un estándar a nivel mundial respecto a la clasificación de las empresas, pero se toman en cuenta dos criterios principales: cualitativos y cuantitativos. Los primeros se refieren a modelos de gestión, métodos de producción y relaciones productivas, mientras que los segundos hacen referencia a indicadores como el número de empleados, ventas anuales y activos totales. En la actualidad México se rige por la normativa de 2009, según la cual, el país acude a dos indicadores principales: plantilla y sector económico. Así que las micromepresas son las que cumplen requisito de una plantilla inferior a 10 personas en los sectores de manufacturera, comercio y servicio; las pequeñas son las de menos de 50 personas en plantilla en los sectores de manufacturera y servicio, y menos de 30 en comercio; y las medianas empresas son las de menos de 100 empleados en plantilla en comercio y servicio y más de 50 y menos de 250 en el sector de manufacturera. Se muestran específicamente en el Cuadro 1:

\footnotetext{
${ }^{2}$ Lawrence Douglas \& Taylor Hanse. Los orígenes de la industria maquiladora en México. Comercio Exterior, noviembre de 2003, P1051.

Orientando. Temas de Asia Oriental. Sociedad, Cultura y Economía. Revista editada por el Centro de Estudios
} 
Cuadro 1 Criterios de clasificación para las empresas mexicanas

\begin{tabular}{|l|l|l|l|}
\hline $\begin{array}{l}\text { tamaños } \\
\text { sectores }\end{array}$ & $\begin{array}{l}\text { Sector de } \\
\text { manufacturera }\end{array}$ & $\begin{array}{l}\text { Sector de } \\
\text { comercio }\end{array}$ & $\begin{array}{l}\text { Sector } \\
\text { servicio }\end{array}$ \\
\hline Microempresas & $\mathbf{0 - 1 0}$ & $\mathbf{0 - 1 0}$ & $\mathbf{0 - 1 0}$ \\
\hline $\begin{array}{l}\text { Pequeñas } \\
\text { empresas }\end{array}$ & $11-50$ & $11-30$ & $11-50$ \\
\hline $\begin{array}{l}\text { Medianas } \\
\text { empresas }\end{array}$ & $\mathbf{5 1 - 2 5 0}$ & $31-100$ & $51-100$ \\
\hline $\begin{array}{l}\text { Grandes } \\
\text { empresas }\end{array}$ & $\geq 251$ & $\geq 101$ & $\geq 101$ \\
\hline
\end{tabular}

Fuente: INEGI, 2009.

Las Mipymes desempeñan el papel fundamental en la promoción del desarrollo económico del país y en el aumento del empleo. Según los datos de PROMEXICO, la tasa de contribución al PIB de las Mipymes en 2018 alcanzó el 52\%, generando casi el 64\% de la totalidad de los empleos del país. Conforme a las estadísticas del Instituto Nacional de Estadística y Geografía (INEGI), en 2018, el número total de empresas en México llegó a 4, 180, 986, con cerca de 20 millones de empleados. De ellas, 11, 309 empresas son de gran tamaño, que han ocupado el porcentaje de $0.20 \%$ del total y han contratado a 7, 234, 072 empleados, representando el 36\% de empleados totales del país; las Pymes totalizan 111, 958, con el porcentaje del 2.6\% de empresas y 3, 223, 928 empleados, representando el $16.14 \%$ de empleados contratados; las microempresas y sus empleados fueron 4, 057, 719 y 9, 505, 392 respectivamente, con proporción del $97.2 \%$ y 47.60\%. Se encontrarán los detalles en el Cuadro 2:

Orientando. Temas de Asia Oriental. Sociedad, Cultura y Economía. Revista editada por el Centro de Estudios China-Veracruz de la Universidad Veracruzana, México (Centro de Estudios APEC) / año 10 / número 21/ 


\section{Cuadro $2 \quad$ Empresas y sus empleados en México}

\begin{tabular}{|l|l|l|l|l|}
\hline \multirow{2}{*}{ Tamaño } & \multicolumn{2}{|c|}{ Empresas } & Empleados \\
\cline { 2 - 5 } & Número & Porcentaje & Número & Porcentaje \\
& & $(\%)$ & & $(\%)$ \\
\hline Microempresas & $4,057,719$ & 97.20 & $9,505,392$ & 47.60 \\
\hline Mipymes & 111,958 & 2.60 & $3,223,928$ & 16.14 \\
\hline Grandes & 11,309 & 0.20 & $7,234,072$ & 36.20 \\
\hline Empresas & & & $19,963,392$ & 100.00 \\
\hline
\end{tabular}

Fuente: Presencia de las pequeñas y medianas empresas en los sectores exportadores de México, 2018.

En términos de la distribución sectorial, las proporciones de las Mipymes mexicanas en los sectores comercial, manufacturero y de servicios son $51 \%$, 36\% y $13 \%$, y en el comercio se concentra el mayor número de empresas. En cuanto a empleos, personal ocupado en Mipymes por sectores de comercio, manufactura y servicios ocupan respectivamente el $41 \%, 38 \%$ y $21 \%$ del total y también es el sector de comercio donde se ofrecen más empleos. Se encontrarán más detalles por Gráficos 1 y 2.

Orientando. Temas de Asia Oriental. Sociedad, Cultura y Economía. Revista editada por el Centro de Estudios China-Veracruz de la Universidad Veracruzana, México (Centro de Estudios APEC) / año 10 / número 21/ 


\section{Gráfico 1}

Mipymes por sector en México

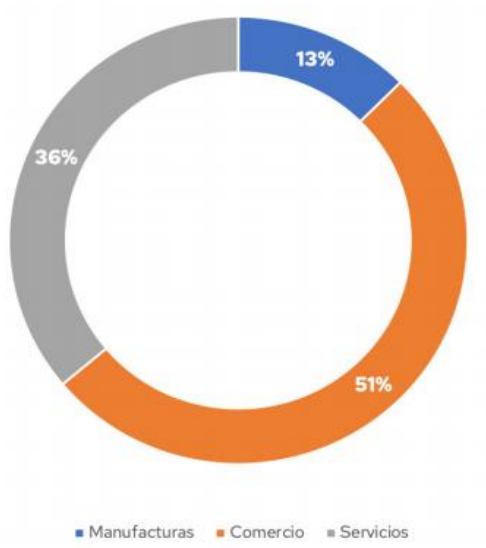

Gráfico 2 Personal ocupado en Mipymes

por sector en México

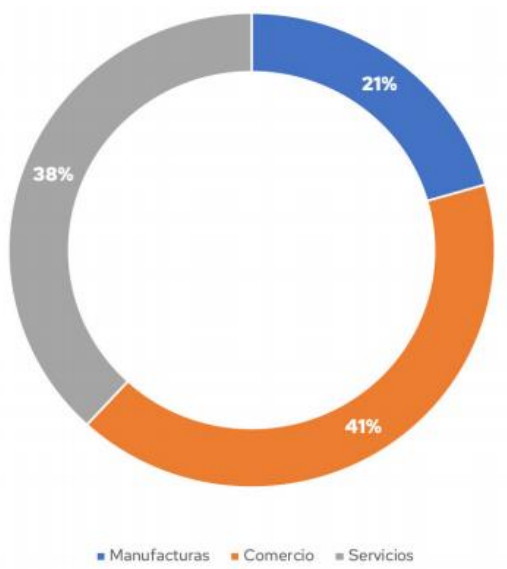

Fuente: INEGI, 2018.

En términos de la distribución geográfica, las Mipymes mexicanas se encuentran concentradamente en las regiones industriales más desarrolladas, como el Estado de México, la Ciudad de México, el Estado de Veracruz, Jalisco y Puebla. En Nayarit, Quintana Roo, Campeche, Colima y Baja California Sur y otros estados industriales y comerciales menos desarrollados solo se distribuyen el 3.7\% de las Mipymes del país. Debido a la cercanía geográfica con los Estados Unidos, se concentran más Pymes en el norte que en el su rde México.

\section{Impactos de la pandemia en las Mipymes mexicanas}

La pandemia del coronavirus ha tenido un gran impacto en la macroeconomía de México, y la magnitud de dicho impacto se identifica principalmente en tres etapas. La primera etapa es la inicial en la que se cerraron fronteras en algunos países y se cancelaron los vuelos internacionales. El sector de servicios, especialmente el de turismo, es el que más ha sufrido y las actividades económicas de los principales destinos turísticos como Quintana Roo y Baja California Sur están afectadas. Desde entonces, mayor número de países asiáticos y europeos Orientando. Temas de Asia Oriental. Sociedad, Cultura y Economía. Revista editada por el Centro de Estudios 
comienzan a tomar medidas de cuarentena y el impacto negativo va extendiéndose al sector manufacturero, especialmente a los asociados estrechamente con las cadenas de valor globales. En marzo, las actividades manufactureras tuvieron las primeras caídas de $-4.7 \%$ en compararción con el mes previo anterior y el IGAE (Indicador Global de Actividad Económica) también se contrajo en un $1.3 \%$.

En la segunda instancia, debido a la suspensión de todas las "actividades no esenciales", el crecimiento económico de México se ha desacelerado de manera significativa, en el sentido de que las industrias manufacturera y de servicios se han frenado aún más, y más sectores económicos se han visto obligados a suspender la producción hasta junio e incluso hasta más tarde. Antes de junio, la producción en sectores de la minería, la construcción, la automoción y la aeroespacial se convirtió en "actividades no esenciales" y se vio obligada a detenerse en México. Las caídas del $25 \%$ y $14 \%$ en la producción de sectores de industrias y servicios se tradujeron en la disminución del 17.3\% en el IGAE de México respecto a marzo, que es la mayor contracción mensual a lo largo de la historia. En mayo, el IGAE siguió contrayéndose, resgistrándo el 2.6\% menos que en abril. En el sector industrial, el índice de actividad industrial en mayo disminuyó 1.8\% desde abril, porque las caídas productivas de la construcción y las manufacturas son 33\% y 31\%, respectivamente.

Desde principios de julio hasta la fecha, México se encuentra en la tercera etapa, y algunos sectores económicos han reanudado la producción. El continuo aumento de los casos de infección hace imposible al Gobierno reiniciar completamente actividades a corto plazo, de ahí que "el desarrollo con la pandemia" ha llegado a ser la nueva normalidad de la economía mexicana. Muchas organizaciones mexicanas creen que las empresas nacionales no van a recuperar su producción hasta el año $2022^{3}$.

La pandemia del coronavirus ha llevado al débil crecimiento macroeconómico en México y al cierre de muchas empresas, sobre las Mipymes, que se han visto más afectadas

\footnotetext{
${ }^{3}$ Gerardo Hernández. Crisis del Covid-19 dejó sin trabajo a 8.1 millones de empleados de micronegocios. 2 de Junio de 2020.

https://factorcapitalhumano.com/leyes-y-gobierno/crisis-del-covid-19-dejo-sin-trabajo-a-8-1-millones-deempleados-de-micronegocios/2020/06/

Orientando. Temas de Asia Oriental. Sociedad, Cultura y Economía. Revista editada por el Centro de Estudios
} China-Veracruz de la Universidad Veracruzana, México (Centro de Estudios APEC) / año 10 / número 21/ 
negativamente por la pandemia. A continuación, se aborda el tema detalladamente desde las tres perspectivas: el comercio, el capital y el empleo.

En primer lugar, desde la perspectiva comercial, la pandemia ha afectado gravemente las importaciones y exportaciones de las Mipymes mexicanas. En términos de importaciones, los productos intermedios de las empresas mexicanas provienen principalmente de China y los Estados Unidos ${ }^{4}$, por lo tanto, la caída de exportaciones chinas y la interrupción del suministro de productos intermedios desde los dos países por la pandemia suponen un sinfín de dificultades productivas para las empresas manufactureras mexicanas. Por un lado, según las estadísticas de la Conferencia de las Naciones Unidas sobre Comercio y Desarrollo (UNCTAD), México ha llegado a ser la octava economía más afectada por la interrupción de la cadena global, ya que el $60 \%$ de las importaciones mexicanas de China son productos manufactureros como electrodomésticos, repuestos, maquinaria y equipos. Las industrias electrónica y automotriz también dependen en gran medida de la importación de los repuestos chinos. Datos relevantes de la encuesta también muestran que desde la pandemia, el $45 \%$ de las Mipymes mexicanas han enfrentado una escasez de componentes electrónicos en China, y al menos 12 empresas se han visto obligadas a suspender la producción.

Por otro, la interrupción del suministro por parte de los Estados Unidos también resultó en una pérdida de US \$ 1.81 mil millones en las exportaciones de maquinaria y equipos de México, y una pérdida de 936 millones de dólares en las de automóviles y repuestos ${ }^{5}$. En términos de exportaciones, 34 países dejaron de importar bienes desde México y las pérdidas exportadoras de las empresas mexicanas totalizaron US \$ 46, 500 millones. Los automóviles, equipos electrónicos, farmacéuticos y equipos de medicamentos son las industrias más globalizadas de México, por lo tanto, las exportaciones también son las más afectadas $^{6}$. El hecho de que las exportaciones chinas de productos intermedios cayeron $2 \%$

${ }^{4}$ Fortune.La caída de exportaciones chinas por el coronavirus impacta a México. 13 de marzo de 2020
https://www.fortuneenespanol.com/finanzas/exportaciones-mexico-afectadas-coronavirus/
${ }^{5}$ 国际贸易中心.中小企业竞争力展望 2020 : COVID-19 : 大封锁及其对小企业的影响. 2020. 第 9 页
${ }^{6}$ Roberto Morales. Propiciará Covid-19 impacto crítico en las exportaciones. Ansley. 23 de marzo de 2020
https://www.eleconomista.com.mx/empresas/Propiciara-Covid-19-impacto-critico-en-las-exportaciones-
Orientando. Temas de Asia Oriental. Sociedad, Cultura y Economía. Revista editada por el Centro de Estudios China-Veracruz de la Universidad Veracruzana, México (Centro de Estudios APEC) / año 10 / número 21/ 
en febrero condujo a que las pérdidas directas de exportación de las empresas mexicanas ascendieron a US \$ 1.369 millones. Como las Pymes mexicanas exportan el $80 \%$ de sus productos al mercado de Estados Unidos, la desaceleración de la economía de Estados Unidos ha afectado aún más el desempeño de exportación.

En términos generales, el impacto de la pandemia en la importación y exportación de las Mipymes de México se trasmite por dos mecanismos: la demanda y el precio. En términos de la demanda, como el mercado de exportación de México depende en gran medida de los Estados Unidos, que ha sufrido mayores consecuencias negativas desde la Gran Depresión de la década de 1930. La reducción de los gastos de los consumidores y el aumento del proteccionismo durante la pandemia han hecho que la demanda del mercado en Estados Unidos por parte de otros países haya caído drásticamente.

En cuanto al mecanismo del precio, la pandemia provocó que el peso mexicano frente al dólar estadounidense alcanzara al nivel mínimo histórico. Según el informe emitido por el Fondo Monetario Internacional (FMI) en julio, el tipo de cambio del peso mexicano frente al dólar estadounidense cayó alrededor de en un $20 \%{ }^{7}$. En comparación con el inicio del año, el peso mexicano ha caído más del 30\%, y los principales índices bursátiles del mercado de valores también han alcanzado los puntos de cierre más bajos en los últimos diez años ${ }^{8}$ El crudo estadounidense West Texas Intermediate (WTI) se desploma y se ha dejado un 300\% por primera vez en la historia el 20 de abril de 2020, cotizando en negativo en los 37.63 dólares por barril ${ }^{9}$. La brusca caída de los precios internacionales del crudo tuvo grandes impactos en las empresas petroleras en México.

${ }^{7}$ 中国金融新闻网. IMF 发布报告称：美元主导作用将加剧疫情对经济影响. 2020 年 7 月 22 日. https://www.financialnews.com.cn/hq/cj/202007/t20200722_196344.html

8 新华网. 疫情下墨西哥经济遭受“多重打击”. 2020 年 4 月 18 日. http://www.xinhuanet.com/fortune/2020-04/18/c 1125874820.htm

${ }^{9}$ Vicente Nieves. ¿Por qué el petróleo Texas de Estados Unidos se ha hundido mucho más que el crudo Brent europeo?, 21 de abril de 2020.

https://www.economiahoy.mx/mercados-eAm-mexico/noticias/10492927/04/20/Por-que-el-petroleo-Texasde-Estados-Unidos-cae-el-doble-que-el-crudo-Brent-europeo.html

Orientando. Temas de Asia Oriental. Sociedad, Cultura y Economía. Revista editada por el Centro de Estudios 
En segundo lugar, desde la perspectiva de capital, la liquidez de las Mipymes se ve afectada y los canales de financiamiento están bloqueados. Por una parte, debido a que un gran número de Pymes mexicanas está estrechamente incorporado a la cadena de suministro internacional por el T-MEC, la obstrucción a las exportaciones ha conducido a la falta de liquidez en las empresas y a la ruptura en la cadena de capital. Por esto les resulta difícil continuar la producción, completar los pedidos y corren el riesgo de declararse en quiebra. Abraham Vergara, experto financiero de la Universidad Russell en Estados Unidos, predice que al menos el $40 \%$ de las Mipymes mexicanas habrá sido afectado por la pandemia en la liquidez. Además, la "Encuesta Nacional sobre Productividad y Competitividad de las Micro, Pequeñas y Medianas Empresas de México" (ENAPROCE) mostró que con la llegada de la pandemia, más de 4 millones de microempresas mexicanas apenas y pueden mantener sus operaciones, con una ganancia neta semanal de solo $\$ 77^{10}$.

Por otra parte, el costo de financiación de las empresas ha aumentado de manera considerable. La Junta de Gobierno del Banco de México (Banxico) señaló que, durante la pandemia, la tasa de morosidad de la cartera de préstamos bancarios y no bancarios de las empresas nacionales mexicanas había incrementado mucho. En el primer semestre de 2020, el crédito bancario total de las empresas nacionales en México disminuyó en más de 10 mil millones de pesos, y el número de Mipymes que recibieron créditos bancarios se redujo drásticamente. Al mismo tiempo, los bancos han impuesto requisitos más estrictos para las Mipymes, y la diferencia en los tipos de interés de los préstamos con las grandes empresas también ha aumentado.

Además, la política pública de México no fomenta la inversión privada y en el país no existen políticas anticíclicas de ajuste fiscal en el sector productivo, lo que no solo perjudica la recuperación de las actividades productivas a corto plazo, sino también tiene un potencial impacto negativo en el desarrollo económico a largo plazo. Desde julio de 2018 hasta marzo de 2020, la inversión extranjera de México disminuyó un 16\% y el monto total

\footnotetext{
${ }^{10}$ Araceli Almaraz Alvarado. Recuperación Productiva y Empresarial Post COVID-19: Las micro, pequeñas y medianas empresas. Documento de contigencia de El Colegio de la Frontera Norte. Tijuana, B.C.14 de mayo 2020.

Orientando. Temas de Asia Oriental. Sociedad, Cultura y Economía. Revista editada por el Centro de Estudios
} 
de inversión extranjera absorbida en abril y en mayo continuó disminuyendo hasta $32 \%{ }^{11}$. Todo esto ha provocado la contracción de los canales de financiamiento para las Mipymes mexicanas.

Lo que ha obstaculizado el financiamiento de las Pymes en México tiene mucho que ver con el desfavorable entorno financiero del país. Aún no se ha establecido un sistema de política financiera institucionalizado que propicie el desarrollo de las pequeñas entidades. En el contexto de la crisis económica, se ha incrementado la asimetría de información entre las instituciones financieras y las Pymes, así que es más común el "miedo a otorgar préstamos" por parte del banco; aparte de eso, tal comportamiento se atribuye a la estructura financiera irrazonable de las Mipymes, el alto riesgo en sus operaciones y asuntos financieros, así como la falta de talentos administrativos en las mismas.

En tercer lugar, desde la perspectiva del empleo, la pandemia ha provocado un aumento sustancial de desempleo en las Mipymes. Según los datos del Instituto Mexicano del Seguro Social (IMSS), se registró un pérdida total de 347, 000 empleos en los sectores de manufactura, servicios y construcción del país desde el 13 de marzo hasta el 6 de abril de 2020. Los Estados de Baja California, Sonora, Chihuahua, Coahuila y Tamaulipas son los lugares donde se conglomeran Pymes exportadoras de procesamiento y se registró la tasa de desempleo más alta del país. La Encuesta Telefónica de Ocupación y Empleo (ETOE) publicado por INEGI muestra que el número de empleados en microempresas en marzo de 2020 fue de 22.8 millones, pero cayó a 14.7 millones en abril, con una disminución interanual de 8.1 millones. En marzo y abril de 2020, el número en las pequeñas empresas fue de 8.5 millones y 6.2 millones, con una disminución de 2.3 millones; y el número de empleados en las medianas empresas en marzo y abril de 2020 fue de 5.5 millones y 5 millones. Mientras tanto, los empleados en las grandes empresas pasaron de 5.1 millones a 3.8 millones. Cabe mencionar que desde el brote de coronavirus, el número total de desempleados en México ha alcanzado los 12.2 millones. Las microempresas son las más afectadas por la pandemia, que

\footnotetext{
${ }^{11}$ La pandemia ya pega a los créditos para familias y pymes. 27 de agosto de 2020. https://expansion.mx/economia/2020/08/27/la-pandemia-ya-pega-a-los-creditos-para-familias-y-pymes Orientando. Temas de Asia Oriental. Sociedad, Cultura y Economía. Revista editada por el Centro de Estudios
} 
representan el 66\% del total de desempleo en el país; seguidas de las pequeñas empresas, que representan el 19\%; las grandes empresas, con el 11\%; y finalmente las empresas medianas alrededor del $4 \%^{12}$. Se muestran los detalles en el Cuadro 3:

\section{Cuadro 3 Empleados en empresas de differentes tamaño en México}

\section{(Unidad: millones)}

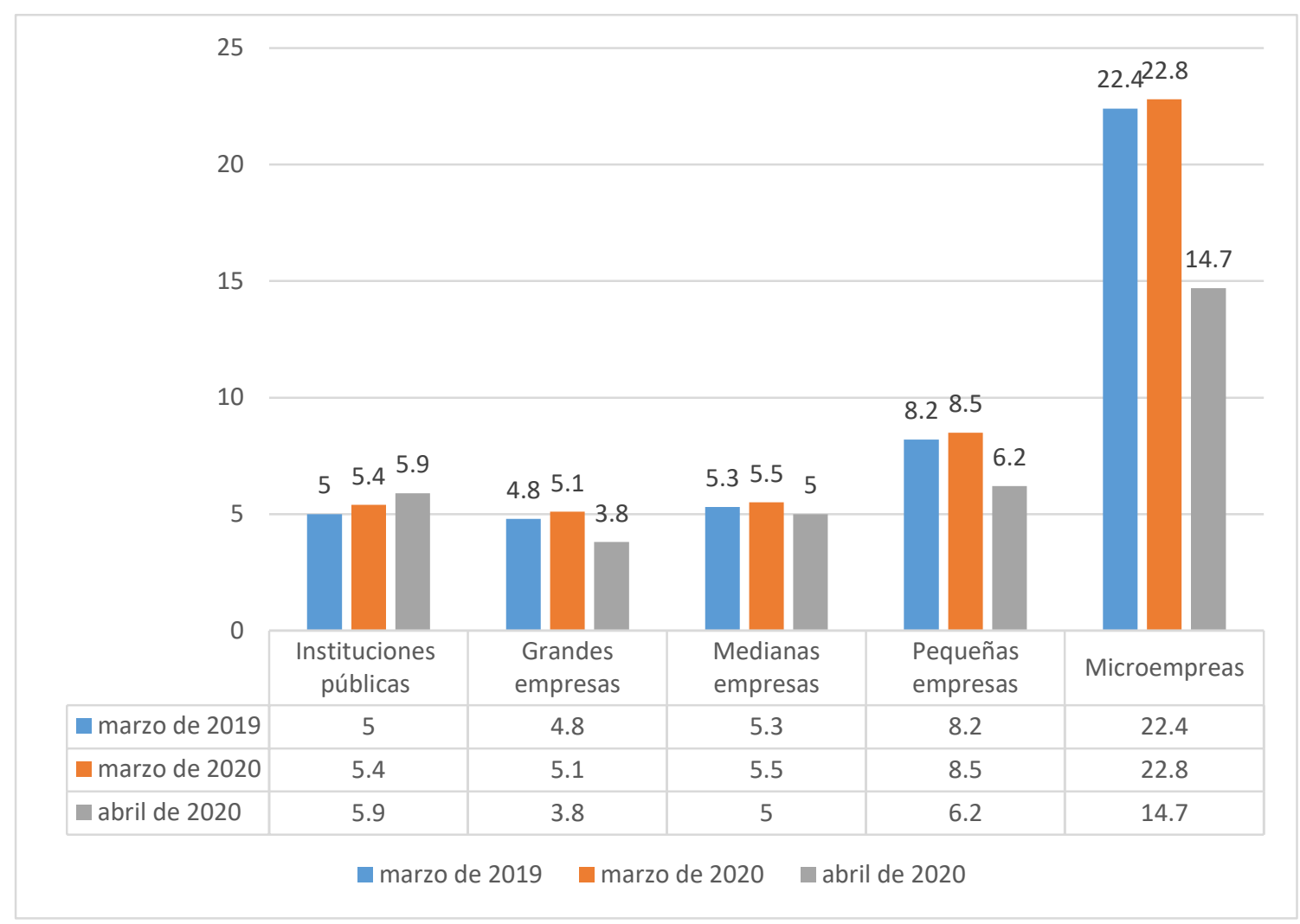

Fuente: La Encuesta Telefónica de Ocupación y Empleo, INEGI.

Además, la Organización Internacional del Trabajo (OIT) pronosticó que el porcentaje de la población desocupada del país en la población económicamente activa (PEA) aumentaría de $3.4 \%$ a $4.1 \%$ en 2021 , y la tasa de desocupación de la población

\footnotetext{
${ }^{12}$ Gerardo Hernández. Crisis del Covid-19 dejó sin trabajo a 8.1 millones de empleados de micronegocios. 2 de junio de 2020.

https://factorcapitalhumano.com/leyes-y-gobierno/crisis-del-covid-19-dejo-sin-trabajo-a-8-1-millones-deempleados-de-micronegocios/2020/06/

Orientando. Temas de Asia Oriental. Sociedad, Cultura y Economía. Revista editada por el Centro de Estudios
}

China-Veracruz de la Universidad Veracruzana, México (Centro de Estudios APEC) / año 10 / número 21/ 
económicamente activa sería de $1.7 \%$. Como resultado, el número total de desempleados en los sectores formales en México en 2021 llegaría a 487, 000³.

No es difícil entender que las microempresas y las pequeñas empresas son las más afectadas por la pandemia, pues tienen capacidades operativas insuficientes, bajos niveles técnicos y relativamente débiles capacidades de anti-riesgo. Además, con el aumento de la población sin empleo en las Pymes se notaría un gran impacto negativo en la fiscalidad del gobierno, ya que el impuesto sobre la renta de las personas físicas (ISR), el impuesto al valor agregado (IVA) y el impuesto especial de producción y servicios (IEPS) para personas físicas y jurídicas, en total representa, el 57\% de los ingresos fiscales del Gobierno mexicano. El disparo de desempleados en el país y la disminución de los pagos de impuestos corporativos conducen a la reducción sustancial de las recaudaciones fiscales del Gobierno. Conforme a los datos del Laboratorio de Análisis en Comercio, Economía y Negocios (Lacen) de la Universidad Nacional Autónoma de México, solo en abril de 2020, la recaudación de los tres impuestos anteriores se redujo 953 mil millones de pesos ${ }^{14}$ y tal reducción durante la pandemia también ha afectado la capacidad del gobierno para subsidiar y ayudar a las empresas a cierto plazo.

\section{Medidas en respuesta a la crisis}

En respuesta al impacto negativo de la pandemia, el Gobierno mexicano celebró una conferencia de la recuperación económica en la Ciudad de México del 27 al 29 de abril de 2020 y formuló las metas para la recuperación económica, que consistían en minimizar el costo laboral para responder a los estragos de la contingencia y reducir el impacto adverso de la crisis al proteger a los trabajadores y proporcionar subsidios a los pobres. Por

\footnotetext{
${ }^{13}$ Apoyar a las pymes ayudará a la economía después del Covid-19.11 de mayo de 2020. http://www.foroconsultivo.org.mx/FCCyT/boletines-de-prensa/apoyar-las-pymes-ayudará-laeconom\%C3\%ADa-después-del-covid-19

${ }^{14}$ Julio Gutiérrez. Más de un millón de desempleados en México por Covid-19.15 de mayo de 2020. https://www.jornada.com.mx/2020/05/14/economia/018n2eco

Orientando. Temas de Asia Oriental. Sociedad, Cultura y Economía. Revista editada por el Centro de Estudios 
consiguiente, se han introducido una serie de políticas favorables a las empresas, cuyo objetivo es ayudar a las Mipymes a reducir la presión financiera, así como restaurar el crecimiento económico lo antes posible en la era post-pandemia.

En cuanto a la política macroeconómica, el Gobierno utilizó herramientas fiscales y monetarias para implementar un paquete de medidas de estímulo de emergencia. Con la llegada del coronavirus, el Banco de México ha bajado repetidamente la tasa de interés de referencia, para darle mayor importancia al rol de la política monetaria y adecuar la tasa de interés de política a la meta de inflación. En el contexto de la fuerte contracción de la economía doméstica en el segundo trimestre, el 13 de agosto el Gobierno mexicano anunció la reducción de la tasa de interés de referencia de 5\% a 4.5\%, llegando al nivel más bajo durante cuatro años tras seis caídas consecutivas en el mismo año. Además, el Gobierno también brindó apoyo financiero a las Mipymes nacionales a través del Fondo de Desarrollo Social (Fondeso). En mayo de 2020, el monto disponible del fondo alcanzó los 500 millones de pesos, y desde entonces se ha otorgado un total de 1 millón de préstamos con límite de 25 mil pesos y un período de gracia de tres meses para las pequeñas empresas. Poco después, el Gobierno mexicano declaró una vez más la provisión de 50, 000 microcréditos con un período de gracia de 4 meses para el pago de préstamos a pequeñas empresas de la Ciudad de México ${ }^{15}$. En la tercera etapa del desarrollo de la epidemia, el Gobierno también prestó el apoyo financiero a microempresas a través de proyectos como Tandas del Bienestar y Créditos a la Palabra.

Por parte de las instituciones comerciales nacionales mexicanas, éstas ofrecieron diversos proyectos de apoyo para las Mipymes. El Consejo Mexicano de Negocios (CMN) y el Banco Interamericano de Desarrollo de Inversiones (BID Invest) lanzaron conjuntamente un proyecto de préstamo a mediano plazo por un total de US\$ 12 mil millones (aproximadamente 290 mil millones de pesos), que se utiliza principalmente para brindar respaldo crediticio a 30 mil Mipymes nacionales. El plazo de amortización del préstamo es

\footnotetext{
${ }^{15} \mathrm{CDMX}$ ofrece 50 mil microcréditos a Pymes por crisis de Covid-19.25 de marzo de 2020. https://bajopalabra.com.mx/cdmx-ofrece-50000-microcreditos-a-pymes-por-crisis-de-covid-19

Orientando. Temas de Asia Oriental. Sociedad, Cultura y Economía. Revista editada por el Centro de Estudios
} 
de 90 días y se permite liquidar tanto en pesos mexicanos como en dólares estadounidenses. Cabe mencionar que las medidas anteriores son simples y fáciles de operar, y han brindado a las Mipymes mexicanas un mecanismo de crédito preferencial para responder a las emergencias de salud y la producción de las empresas, así como promover la recuperación económica.

A nivel de instituciones internacionales, la Corporación Andina de Fomento (CAF) intentó mitigar el impacto de la epidemia en el sistema financiero interno de México y aumentó los apoyos técnico y financiero a las empresas mexicanas a través de Fideicomisos Instituidos en Relación con la Agricultura (FIRA). La institución fiduciaria dio prioridad al apoyo a la banca de desarrollo local y asignó fondos a más de 42 empresas productoras en todo el país, especialmente a las Mipymes, satisfaciendo en cierta medida sus necesidades de financiamiento e inversión. Al mismo tiempo, el Banco Interamericano de Desarrollo (BID) lanzó el Fondo Especial para Financiamientos Agropecuarios (FEFA), que resulta eficaz para resolver los problemas de financiamiento empresarial y prestó el apoyo financiero a las Mipymes agrícolas en México, incluyendo sectores de producción de exportación estratégicos e intensivos en manos de obra como brócoli, nueces, fresas, papas, aguacates, pimientos, cebada, pesca, ganadería y silvicultura, etc ${ }^{16}$.

Finalmente, desde la perspectiva de las mismas empresas, la pandemia ha impulsado la transformación digital de las Mipymes nacionales y ha acelerado la promoción y el uso del comercio electrónico y las plataformas digitales. Debido a la propagación epidémica en la economía global, el desarrollo económico se enfrenta a una gran incertidumbre en el futuro. Con el fin de adaptarse mejor a los cambios derivados de la contingencia, un número considerable de Mipymes en México han comenzado a llevar a cabo la "transformación digital", lo que se refleja en que empresas que solo se valían de ventas convencionales incorporaron las ventas en línea a los ajustes de planificación, y las empresas que ya contaban con esta estructura fortalecieron aún más el modelo, principalmente al valerse de las redes

${ }^{16}$ COVID-19: CAF ratifica su compromiso con las Pymes mexicanas.julio de 2020 https://www.caf.com/es/actualidad/noticias/2020/07/covid-19-caf-ratifica-su-compromiso-con-las-pymesmexicanas/

Orientando. Temas de Asia Oriental. Sociedad, Cultura y Economía. Revista editada por el Centro de Estudios 
sociales para la promoción de productos y atraer a más clientes para conseguir mejores ventas. Las estadísticas del "Informe de la Encuesta de Ventas Online de Pymes de México 2020 "17 muestran que en julio de 2020, cerca del 60\% de las Pymes mexicanas han adoptado el modelo de ventas virtuales, registrando un aumento del $94.6 \%$ respecto al año anterior ${ }^{18}$. Tras el brote de Covid-19, las Pymes cuyas ventas online representaban más del $31 \%$ de las ventas corporativas ocupan el $18.3 \%$ del total del país, mientras que en junio de 2020 la proporción aumentó al 31,5\%, por lo tanto, se puede concluir que la epidemia ha incrementado en cierta medida el reconocimiento de los modelos de venta online entre las pequeñas empresas.

Frente a la "nueva normalidad" de la economía post-crisis, el comercio electrónico ayudará a mejorar el posicionamiento de las Pymes, ampliar las categorías de sus ventas, así como mejorar sus estrategias comerciales. No nos extraña que algunas empresas aún mantengan una actitud conservadora hacia este sistema ya que los costos logísticos en México son relativamente altos y muchas veces exceden los del producto, lo que reduce los márgenes de ganancia para la empresa. Además, las plataformas de venta en línea cobrarán comisiones más altas. En tercer lugar, los modelos de venta de plataformas no resultan adecuados para los alimentos perecederos.

\section{Planificaciones y perspectivas en la era post-pandemia}

Desde que la Organización Mundial de la Salud OMS) anunció el día 11 de marzo de 2020 que la nueva epidemia de neumonía había llegado al tipo "pandemia", ésta ha modificado de manera amplia el mapa económico mundial a un ritmo y escala sin precedentes y ha influido profundamente en la tendencia de desarrollo económico de todos los países. Actualmente, se anuncian cada día un gran número de nuevos casos en México y todavía es difícil controlar

\footnotetext{
${ }^{17}$ En el informe, la encuesta se extiende del 18 de mayo al 6 de junio de 2020, y es dirigida a 377 empresas manufactureras en México con ventas anuales inferiores a 50 millones de pesos.

${ }^{18}$ Forbes. Covid-19 detona entrada de pymes al comercio electrónico. 7 de julio de 2020.

https://www.forbes.com.mx/negocios-covid-19-interes-pymes-ecommerce/

Orientando. Temas de Asia Oriental. Sociedad, Cultura y Economía. Revista editada por el Centro de Estudios
} 
la extensión de la epidemia de manera efectiva a corto plazo. Según La Confederación de Cámaras Industriales de los Estados Unidos Mexicanos (CONCAMIN), durante la epidemia, al menos 1.17 millones de empresas en México quebraron, sobre todo Pymes ${ }^{19}$. Como la epidemia aún no ha tocado fondo y el sistema de producción nacional de México no ha atravesado la etapa más severa, muchas empresas han comenzado a replantear y reformular estrategias de desarrollo a mediano y largo plazo bajo la "nueva normalidad" en la era postepidemia, a saber:

En primer lugar, el Gobierno elaborará unas políticas públicas más inclusivas. Como señaló Santiago Levy, ex-vicepresidente del Banco Interamericano de Desarrollo y otros analistas de instituciones de investigación, la formulación de políticas públicas en el contexto de la epidemia debería tener más en cuenta los trabajos del sector informal y conceder mayor importancia a las Pymes. Se deberían brindar el apoyo financiero a los más vulnerables por transferencias incondicionales de pagos. Este respaldo debería estar incluido en el programa de asistencia económica. Las estadísticas arrojan que actualmente 31 millones de personas en México están trabajando en los sectores informales. Lo que resulta curioso es que, aunque la epidemia de coronavirus ha ejercido un gran impacto en los empleos de México, el aumento en la tasa de desempleo de los trabajos oficiales haya sido menos de lo esperado ${ }^{20}$. Eso se debe principalmente a la gran presencia del sector informal en el mercado laboral mexicano, que en cierta medida amortigua el impacto negativo de la economía en el empleo formal.

En segundo lugar, se diseñará un plan de desarrollo para la "nueva normalidad" en la era post-epidemia. Ante la continua extensión de la pandemia, las economías mundiales se enfrentan a un dilema, que consiste en la elección entre preservar la economía y prevenir la epidemia. La estrategia de México también ha experimentado una modificación, desde el enfoque en la prevención de epidemias de carácter "contención” hasta el de la recuperación gradual de las actividades económicas luchando contra la epidemia. La Jornada Nacional de

\footnotetext{
${ }^{19}$ 新华网. 疫情下墨西哥经济遭受“多重打击”. 2020 年 4 月 18 日 http://www.xinhuanet.com/fortune/202004/18/c_1125874820.htm

${ }^{20}$ Gerardo Esquivel. Los impactos económicos de la pandemia en México, julio de 2020, p8.

Orientando. Temas de Asia Oriental. Sociedad, Cultura y Economía. Revista editada por el Centro de Estudios
} 
Recuperación Productiva y Empresarial, formulado por el Gobierno para el período posterior de la epidemia de neumonía brinda a las Mipymes una orientación para reiniciar las actividades productivas. A corto plazo, las empresas pueden superar la crisis solicitando fondos gubernamentales y apoyos financieros, y posteriormente reanudar la producción y operación normales de manera planificada. A mediano y largo plazo, las empresas deberían fortalecer la capacitación de los empleados, mejorar la innovación tecnológica, así como lograr una verdadera transformación y lograr el crecimiento en la era post-crisis.

En tercer lugar, se abrirá la cadena de cooperación industrial entre las Mipymes y las grandes empresas nacionales. Indudablemente, las grandes entidades cuentan con mayor capacidad anti-riesgo y de resistencia a la crisis, gracias a la gran escala de producción y al alto nivel técnico. En la era posterior a la epidemia, las pequeñas y medianas empresas mexicanas deberán fortalecer la cooperación con las empresas de gran escala del mismo sector y configurando, de manera gradual, un panorama en el que las grandes empresas funcionan como líderes, lo que se complementará con las Mipymes que brindarán los apoyos correspondientes y cuentan con incentivos fiscales y políticas de subsidios por parte del Gobierno central. De este modo se logra promover en cierto punto el circuito interno de la empresa a través de la formación de la cadena del mercado nacional y extranjero de manera independiente.

En cuarto lugar, se promoverá sólidamente el desarrollo moderno de las Mipymes. A futuro, la tasa de crecimiento económico será lenta y la pauta cambiará de manera total. Por lo tanto, las Mipymes deberán prestar más atención a desarrollar su propia tecnología, promover la innovación de la producción, la gestión y los servicios, utilizar la tecnología moderna para lograr los avances de manera contiuna, así como crear nuevos fuentes de crecimiento económico para la "nueva normalidad".

Por último, cabería señalar que la aplicación práctica de diversas políticas sirve para responder de manera eficaz a la nueva epidemia del coronavirus. Eso es un trabajo conjunto, pues requeriría no no solo la cooperación y atención de departamentos de producción y los de fiscalidad, sociedad, salud, educación, energía y gobernanza cultural, sino también la Orientando. Temas de Asia Oriental. Sociedad, Cultura y Economía. Revista editada por el Centro de Estudios 
captación de oportunidades para fortalecer la cooperación internacional. Últimamente, ha sido sólida la base de la cooperación económica entre China y América Latina y también particularmente con México. El impacto de la pandemia no afectará a corto plazo la estabilidad ya existente en materia de cooperación económica entre ambas partes.

Por el momento, se ha llegado un consenso de que el Gobieno chino ha actuado de manera rápida y eficiente en el trabajo de control y prevención de la pandemia y ha promovido de manera oportuna la reanudación del trabajo y la producción en el país, por eso sus empresas están relativamente menos afectadas, lo que proporcionará, a nivel micro, un buen modelo para promover la recuperación económica y el desarrollo de las Mipymes mexicanas mediante la cooperación económica y comercial. A nivel macro, el nuevo patrón de desarrollo de "Ciclo interno como el núcleo y la promoción mutua de ciclo dual en ámbitos nacional e internacional" propuesto por el presidente chino Xi Jinping también servirá de referencia sumamente importante para México.

\section{Referencias}

新华网。拉美各国新冠死亡数据为何出现两极分化. 2020 年 8 月 8 http://www.xinhuanet.com/2020-08/08/c_1126343352.htm

新华网。疫情下墨西哥经济遭受”多重打击”。2020 年 4 月 8 http://www.xinhuanet.com/fortune/2020-04/18/c_1125874820.htm

新华网。-37.63 每桶美元！首现”负油价”。 2020 年 4 月 22 日 http://www.xinhuanet.com/fortune/2020-04/22/c_1125888249.htm

中华人民共和国商务部. 墨西哥央行降息 50 个基点. 2020 年 8 月 2 日 http://www.mofcom.gov.cn/article/i/jyjl/1/202008/20200802992769.shtml

中国金融新闻网. IMF 发布报告称: 美元主导作用将加剧疫情对经济影响. 2020 年 7 月

22 日 https://www.financialnews.com.cn/hq/cj/202007/t20200722_196344.html

国际贸易中心. 中小企业竞争力展望 2020：COVID-19：大封锁及其对小企业的影响 .2020 https://www.financialnews.com.cn/hq/cj/202007/t20200722_196344.html

Apoyar a las pymes ayudará a la economía después del Covid-19.11 de mayo de 2020. http://www.foroconsultivo.org.mx/FCCyT/boletines-de-prensa/apoyar-las-pymesayudará-la-econom\%C3\%ADa-después-del-covid-19

Orientando. Temas de Asia Oriental. Sociedad, Cultura y Economía. Revista editada por el Centro de Estudios 
Araceli Almaraz Alvarado. Recuperación Productiva y Empresarial Post COVID-19: Las micro, pequeñas y medianas empresas. Documento de contigencia de El Colegio de la Frontera Norte. Tijuana, B.C.14 de mayo 2020.

CDMX ofrece 50 mil microcréditos a Pymes por crisis de Covid-19. 25 de marzo de 2020. https://bajopalabra.com.mx/cdmx-ofrece-50000-microcreditos-a-pymes-por-crisisde-covid-19

COVID-19: CAF ratifica su compromiso con las Pymes mexicanas. julio de 2020. https://www.caf.com/es/actualidad/noticias/2020/07/covid-19-caf-ratifica-sucompromiso-con-laspymes-mexicanas/

Forbes. Covid-19 detona entrada de pymes al comercio electrónico. 7 de julio de 2020. https://www.forbes.com.mx/negocios-covid-19-interes-pymes-ecommerce/

Fortune. La caída de exportaciones chinas por el coronavirus impacta a México. 13 de marzo de 2020. https://www.fortuneenespanol.com/finanzas/exportaciones-mexicoafectadas-coronavirus/

Gerardo Hernández, Crisis del Covid-19 dejó sin trabajo a 8.1 millones de empleados de micronegocios. junio de 2020. https://factorcapitalhumano.com/leyes-ygobierno/crisis-del-covid-19-dejo-sin-trabajo-a-8-1-millones-de-empleados-demicronegocios/2020/06/

Julio Gutiérrez, Más de un millón de desempleados en México por Covid-19. 14 de mayo de 2020. https://www.jornada.com.mx/2020/05/14/economia/018n2eco

La pandemia ya pega a los créditos para familias y pymes. 27 de agosto de 2020. https://expansion.mx/economia/2020/08/27/la-pandemia-ya-pega-a-los-creditospara-familias-y-pymes

Lawrence Douglas \&Taylor Hanse. Los orígenes de la industria maquiladora en México. Comercio Exterior, noviembre de 2003, P1051. http://revistas.bancomext.gob.mx/rce/magazines/59/7/RCE.pdf

Ricardo Fuentes-Nieva. México y el cornavirus: Pasividad gubernamental en una sociedad desigual, Fundación Carolina, abril de 2020, p4.

Roberto Morales. Propiciará Covid-19 impacto crítico en las exportaciones. Ansley. 23 de marzo de 2020. https://www.eleconomista.com.mx/empresas/Propiciara-Covid-19impacto-critico-en-las-exportaciones-Ansley-20200323-0009.html

Orientando. Temas de Asia Oriental. Sociedad, Cultura y Economía. Revista editada por el Centro de Estudios 